\title{
Desde una canción perdida a una Casandra del tercer milenio, o sea: María Rosa Lojo y la construcción de una identidad
}

\author{
Rosa Maria Grillo ${ }^{1}$
}

Resumen. Desde siempre, Galicia y el Nuevo Mundo parecen predestinados a constituir un binomio inalterable, a partir de aquel Finisterrae tan ibérico y, al mismo tiempo, ubicado más allá de las Columnas de Hércules y fuera del Mare Nostrum. A través de la narrativa autobiográfica y la prosa ensayística de la escritora argentina María Rosa Lojo, se analizan unos cuantos momentos, personajes y topoi de la migración/exilio de gallegos a Argentina.

Palabras clave: María Rosa Lojo; Argentina; Galicia; literatura de la Migración.

[en] From a canción perdida to a Third Millennium Cassandra, or Maria Rosa Lojo building an identity

\begin{abstract}
Galicia and New World always seem destined to constitute an unalterable binomial, from that Finisterrae so Iberian and at the same time already located beyond the Columns of Hercules and outside the Mare Nostrum. Through the autobiographical narrative and the essays by the Argentine writer María Rosa Lojo, a few moments, characters and topoi of the migration/exile of Galicians to Argentina are analyzed.
\end{abstract}

Keywords: María Rosa Lojo; Argentina; Galicia; migration literature.

Sumario. 1. Introducción. 2. Narrativa autobiográfica. 3. Canción Perdida en Buenos Aires al Oeste: encuentros y desencuentros. 4. El viaje buscando raíces. 5. Árbol de familia: el árbol y sus raíces.

Cómo citar: Grillo, R.M. (2021) Desde una canción perdida a una Casandra del tercer milenio, o sea: María Rosa Lojo y la construcción de una identidad, en Anales de Literatua Hispanoamericana 50, 33-39.

\section{Introducción}

Toda la producción narrativa de María Rosa Lojo responde a una exigencia bien presente en la 'nueva narrativa latinoamericana', la que podemos llamar poscolonialista, posmoderna ${ }^{2}$ o, simplemente, 'nueva' hasta que no se encuentren etiquetas más reconocibles y compartidas: intentar resolver una de las contradicciones de la conjuntura que, según el escritor rumano Norman Manea, existe entre "la modernità centrifuga, cosmopolita, e il bisogno centripeto (o, quanto meno, la nostalgia), dell'appartenenza" ["la modernidad centrífuga, cosmopolita, y la necesidad centrípeta (o, al menos, la nostalgia) de pertenencia"] (Manea, 2006: 11). Es decir, el sentimiento o la aspiración a lo 'glocal', presente en la mayoría de sus personajes, que conjuga el deseo de pertenencia que hace hablar de búsqueda de raíces, de integración e identidad, con la nostalgia de una patria lejana y/o inaccessible y el deseo de viajar, de conocer, de confrontarse, como parte constitutiva del ser, especialmente vivo en la clase intelectual para la cual Lojo ha

\footnotetext{
${ }^{1}$ Universidad de Salerno, Fisciano. Italia.

Email: rgrillo@unisa.it

${ }^{2}$ Sin entrar en este debate crítico y estético, me refiero a la que nace como respuesta a la crisis del 'siglo breve', del 'pensamiento fuerte', de la 'verdad única', de la fe ciega en el progreso científico. En cambio, la autora frecuentemente entra en este debate: recordamos su ensayo "Posmodernidad: otra lectura de la "barbarie"” (1996b) y su voz indirecta, expresada por Rosaura en La pasión de los nómades (1995), que a menudo habla de 'posmodernidad', lo que sería un rasgo de autorreferencialidad y de metaficción, muy típicos de esta modalidad literaria: "Tuve que admitir que ningún artilugio tramado en la pasatista y febril post-modernidad podía compararse a ese cristal añejado desde el siglo XVII en los altillos de París y en las ferias de gitanas y de magos más afamados del planeta” (Lojo, 2008: 111).
} 
utilizado la locución de "nomadismo cultural" (Lojo, 1996a: 71-86). Por supuesto, insertándose en y alimentando con su misma historia la tradición argentina, que se ha nutrido de fundaciones y refundaciones, ausencias, vacíos, nostalgias, aislamientos y diásporas: "Reescribir los orígenes: una ya vieja tradición de la novela argentina, reviste de esta manera para mí una múltiple función: reunir y entrelazar, en un texto nuevo, las escrituras de dos mundos: el del suelo de nacimiento, pero también el de la memoria familiar y cultural" (Lojo, 2010b: 229).

Todo esto se encuentra tanto en su producción ensayística como en su narrativa, sea la decididamente autobiográfica, sea las novelas históricas -que constituyen magna pars de su obras de ficción-, en las que a menudo se entrecruzan dos miradas excéntricas que renuevan el género y la interpretación historiográfica de los hechos narrados gracias al encuentro ${ }^{3}$ entre personajes extranjeros y mujeres 'históricas' rescatadas del silencio por la mirada de otra mujer ${ }^{4}$.

Estas dos perspectivas derivan directamente de aspectos biográficos de la autora: como 'exiliada hija', 'hija del exilio' o 'segunda generación del exilio', el suyo es un 'exilio heredado', un exilio de segunda mano, sin el trauma de la guerra y del destierro vivido en carne propia pero, como demonstró hace años ya Susana Rivera (1999) a propósito de los hispanomexicanos ${ }^{6}$, sufriendo un destino de extraterritorialidad que puede llevar fácilmente a un sentimiento de exilio existencial, a sentirse sin patria etc. ${ }^{7} \mathrm{o}$, al contrario, a un fuerte deseo, una necesidad de querer radicarse en la nueva patria. Por otra parte, como mujer, escritora y docente de literatura, ha privilegiado en todas las vertientes de su escritura, creativa y ensayística, a escritoras y a personajes históricos femeninos.

\section{Narrativa autobiográfica}

No nos extraña, por lo tanto, encontrar estas dos perspectivas en su narrativa estricta y declaradamente autobiográfica que a lo largo de casi 30 años -desde Canción Perdida en Buenos Aires al Oeste, 1987, hasta Todos éramos hijos, $2014^{8}$ - ha estructurado una trayectoria humana individual y generacional entre Galicia y Argentina que, junto con su producción ensayística sobre el tema, sin duda se puede leer como metáfora de la historia de Argentina, ya que "[h]ablar de la construcción de la identidad argentina es hablar de la identidad gallega. En algún momento, al decir de Ernesto Sábato, Buenos Aires fue 'la ciudad gallega más grande del mundo'. Por algo se la llamó también 'la quinta provincia', en paralelo con las otras cuatro de la Galicia peninsular: A Coruña, Lugo, Ourense y Pontevedra. El colectivo gallego es el más numeroso de la inmigración española (la segunda después de la italiana)" (Lojo, 2016).

En la obra de María Rosa Lojo podemos reconstruir exactamente estos sentimientos contrastantes de extrañamiento y pertenencia, este trayecto entre una pérdida y una adquisición, y reconstruir una posible Historia entre dos Mundos.

Su genealogía cuenta con dos ramas muy diferentes, como ella misma evidencia en la saga familiar Árbol de familia, separando salomónicamente Terra Pai (2010a: 17-145) de Lengua Madre (2010a: 147-284), pero mi análisis se centrará casi exclusivamente en la primera línea, porque es la Galicia paterna la que le suscita

\footnotetext{
${ }^{3}$ Podemos pensar en Lucio Mansilla y Rosaura en La pasión de los nómades, en Manuela Sáenz y Pedro de Angelis en La Princesa federal, etc.

${ }^{4}$ Sobre este tema Lojo interviene también críticamente, analizando la narrativa histórica escrita por mujeres argentinas: el caso de Lucía Miranda le interesa sobremanera, hasta encargarse de la edición crítica de la Lucía Miranda de Eduarda Mansilla y volver insistentemente sobre su caso, por ejemplo en "Genealogías femeninas en la tradición literaria. Entre la excepcionalidad y la representatividad" (2006), "Universalidad y diferencia. ¿Qué tienen las escritoras para decir?” (2005), "Escritoras argentinas (siglo XIX) y etnias aborígenes del Cono Sur” (2005), "Escribir con ojo de libélula" (2008) etc. También ha dedicado una novela a Eduarda Mansilla, Una mujer de fin de siglo (1999).

${ }^{5}$ Ella misma se define una 'exiliada hija' (2006) en un texto fundamental, una confesión al mismo tiempo que una reivindicación de su específico 'estar en el mundo', entre dos mundos. Sería la suya la última generación de americanos atados al campo circunstancial del exilio español del '39: ni exiliada, ni 'niña de la guerra' -quienes siendo niños acompañaron a sus padres camino del exilio- sino nacida en Argentina, en una 'casa española' de padres exiliados, añadiendo contradicción a contradicción, incertidumbres a incertidumbres, desarraigos propios a desarraigos ajenos.

${ }^{6} \mathrm{Si}$ bien es reciente el discurso crítico en Argentina sobre la línea temática del exilio heredado, no faltan escritores en cuya obra el eje EspañaArgentina es fundamental, desde Horacio Vázquez Rial a Alvaro Abós a Aitana Alberti a Miguel de Torre etc.

${ }^{7}$ Se ha dicho que el verdadero exilio es el lingüístico y por eso muchos intelectuales eligieron países hispanoamericanos. Igualmente, María Rosa Lojo recuerda que su castellano 'castizo' le provocó no pocos traumas en su infancia: “yo hablaba de 'ces' y con 'zetas', de 'tú' y de vosotros, como si acabase de pasar por la aduana. Extranjera en mi propia tierra, fui un objeto de fascinada curiosidad los primeros días de clase [...] No fui el único caso de 'doble identidad' idiomática: ésa era una de las marcas habituales del 'exiliado hijo"” (Lojo, 2006: 91-92).

${ }^{8}$ Su última novela, Solo queda saltar (2018) es independiente de su estricto perfil biográfico pero no de sus temáticas (emigración española a la Argentina de la mitad del siglo pasado) ni de su mundo literario (Isolina, presente ya en el Libro de las Siniguales y en Árbol de familia, aquí se vuelve protagonista y narradora).
} 
las páginas más evocativas y líricas y porque ha dedicado a la Argentina gallega una parte considerable de sus investigaciones y reflexiones. Así, sin menospreciar naturalmente la línea materna -Madrid, Castilla, el Franquismo- podemos aventurar una mayor incidencia de la línea paterna en la genealogía de María Rosa Lojo, gallega y republicana.

Para comprobarlo, es suficiente leer sus propias palabras en una entrevista de hace unos años:

Hay un mundo con el que tengo una profunda conexión afectiva. Galicia es un cosmos, sensación que jamás tuve con el Madrid de mi mamá. Mientras que los relatos de mi padre me transmitían aspectos maravillosos, a veces extraños o siniestros, la experiencia de mi mamá era muy urbana, bastante típica del aislamiento de una persona en una gran ciudad. Papá me hablaba todavía de un mundo rural que se remontaba a principios del siglo XIX. En el caso de mi mamá, no era una memoria tan lejana, pero además estaba contaminada porque era una familia venida a menos que había tenido más dinero y posición, pero que había caído, como el hidalgo de El Lazarillo de Tormes, que tenía que salir a la calle fingiendo que había comido y estaba con el estómago vacío. Esa sensación de irrealidad, de parecer lo que no era, era muy fuerte del lado de mi mamá, y es algo que nunca me fue simpático; mientras que en la familia de mi papá eran campesinos con los pies en la tierra, que negociaban mucho mejor con el mundo real (Lojo, 2010b).

Y seguiré aquí el íter que orgullosamente una 'exiliada hija' de origen gallego ficcionaliza desde la dislocación inicial hasta la integración, si bien sufrida y trágica y sin renegar nunca del germen gallego, casi como una garantía o un sello de fábrica.

\section{Canción Perdida en Buenos Aires al Oeste: encuentros y desencuentros}

Las primeras pruebas, que se mueven indudablemente en el 'espacio autobiográfico' de la circunstancia del exilio, dejan entrever un destiempo y un desarraigo de matriz 'exílica': la poesía en prosa de Visiones (1984), de Forma oculta del mundo (1991) y Esperan la mañana verde (1998), y sobre todo la primera novela, Canción Perdida en Buenos Aires al Oeste (1987), donde la autora habla a través de las voces de seis integrantes de una familia española exiliada en Argentina, que expresan cada uno a su manera, con monólogos, cartas, cuentos, etc., rencores y nostalgias, dramas y vivencias que de la España de la guerra civil se han trasladado a la Argentina de los hijos. La familia se ha hecho añicos - un hermano ha muerto en la guerra de las Malvinas y la hermana se ha alejado desde sus bodas con un alemán'- y Miguel, el otro hijo, al regresar a la casa de los padres para festejar su cumpleaños, evidencia la terrible verdad del aislamiento e incomunicabilidad que reina en la casa y entre los familiares ("El silencio pesa demasiado y ha concluido por ahogar el presente", 1987: 19): la mamá sigue añorando al hijo muerto y el padre se ha quedado atrapado en el recuerdo de la guerra perdida y de su juventud rebelde. Cada uno vive su propio desarraigo y revela el fracaso de un proyecto inacabado, pero apelando a la muerte del hijo como el motivo principal del malestar y de la fractura en las relaciones familiares. En cambio, Miguel manifiesta una forma aguda de exilio existencial, independiente de la muerte del hermano, y de alguna forma dependiente de la condición de 'exiliado hijo', que carga con un pasado español no digerido, un duelo no elaborado ("España, abstracta y lejana y nunca deseada lo suficiente, porque se sabe que en cualquier momento podemos regresar", 1987: 27), cuyas palabras recurrentes son "miedo", "memoria", "nostalgia", "silencio", "piedad", ya que, confiesa, ha llegado a los treinta años sin "plantar un árbol, escribir un libro, tener un hijo"10 (1987: 14):

Yo, Miguel, gallego errante, condenado a añorar los siete mares durante siete siglos [...] Yo, el desterrado de una tierra en donde no nací, el que vive no sólo en su país -triste país- sino en el mundo, como en un hotel [...] hijo pródigo que no es aguardado por padre alguno (1987: 47).

Y ya en estas primeras líneas, en las palabras de Miguel, se asume la identidad gallega como dominante, pero también la imposibilidad de una identidad íntegra porque para Miguel, ni el regreso a la casa de los padres significa recobrar raíces: "encontrarme sin encontrarme. Sé muy bien que todos los espejos de la casa paterna están para mí inexorablemente rotos" (1987: 14). La posibilidad de reconocerse reside solo en la comunidad

\footnotetext{
${ }^{9}$ Rasgo autobiográfico evidente.

${ }^{10}$ Referencia a José Martí: "Hay tres cosas que cada persona debería hacer durante su vida: plantar un árbol, tener un hijo y escribir un libro".
} 
no estrictamente familiar, es decir en el recuerdo de un 'paisaje de la memoria' compartido con su antigua niñera, por supuesto también ella gallega: "Un saber minucioso y popular, de refranes y cantos, de magias desdeñadas [...] Nos sentíamos [...] casi parientes, consanguíneos; quizás por un mismo color de ojos, quizás por una idéntica forma de mirar" (1987: 31).

A pesar de esa fisura de empatía, pero totalmente atada al pasado, Canción perdida... es una novela terrible de incomunicación y soledad, que cierra todo camino hacia el futuro por demasiado dolor allí encerrado; autobiográfica en el fondo, aunque no en los pormenores. Efectivamente, los tonos con que María Rosa Lojo se refiere a sí misma en otros textos son más blandos y, sobre todo, circunscribe la etapa de dificultad y desarraigo a la edad juvenil, negando posibles reflejos autobiográficos profundos en el personaje de Miguel, ya treintañero y con heridas insanables: "Durante mucho tiempo, casi hasta la mayoría de edad, sentí mi permanencia en la Argentina como una estadía transitoria" (Lojo, 2006: 93).

\section{El viaje buscando raíces}

Serán necesarios más de 20 años para que María Rosa Lojo vuelva a esos mismos temas -la búsqueda de identitad individual y de una familia, de un grupo delimitado en el tiempo y en el espacio- con una mirada aparentemente pacificada consigo misma y con su propia historia: será la novela Árbol de familia, explícitamente autobiográfica ya en el título y reconocida como tal en afirmaciones extratextuales ${ }^{11}$.

Entre las dos obras, la 'elaboración del duelo' con la sublimación de la microhistoria individual en la macrohistoria argentina y, sin duda, el primer viaje a España:

Conocer España (bastante tarde, recién a los treinta y nueve años) me tranquilizó mucho, me quitó esa sensación latente de encontrarme en el lugar inadecuado, que arrastraba desde la temprana infancia. Por un lado, me dio una gran paz cumplir el mandato tácito que cargamos todos los hijos de los que se fueron considerándose exiliados. El paradójico, absurdo mandato de 'volver' a un lugar donde no hemos nacido y que no conocemos. Vi y toqué con mis ojos y mis manos. Dejé de idealizar. Ahora no me siento en absoluto desdichada ni descolocada en el sitio donde me tocó nacer (Lojo, 2002a: 214).

Y más:

¿Volver?... Sí que 'volví', después de todo, a ese país en donde nunca había estado. Pero no para siempre [...] Reemplacé la trascendencia por la inmanencia. Encontré, del lado de acá, mitos para deshacer y nuevos mitos para construir, desde la ficción y la poesía. No desoí el llamado del origen: me puse a buscarlo por los caminos de la Historia, pero en la tierra donde había nacido" (Lojo, 2006: 95).

Entre las dos obras, efectivamente, María Rosa Lojo se dedica a hurgar en la historia argentina para contribuir, con sus cuentos ${ }^{12}$ y novelas históricas, a la construcción de una identidad para el país: se adueña de su nueva patria ${ }^{13}$ buscando las raíces de una identidad fragmentada, donde el exiliado del siglo XX es solo el último anillo de una cadena de migraciones y exilios, de fundaciones y refundaciones de ciudades y

11 “[...] es la historia de mi familia; [...] lo que le pasa a una familia de alguna manera les pasa a todaslojo [...] el exilio y la inmigración la han vivido miles y miles de personas. La creación literaria hace que lo privado se vuelva público y lo singular se vuelva universal” (Lojo, 2010a).

${ }^{12}$ Lojo en sus relatos 'históricos' recrea ficcionalmente cada etapa de la presencia española en Argentina y de la constitución de esta última como nación independiente: a la época colonial, por ejemplo, se refieren los tres primeros relatos de Amores insólitos de nuestra historia (2001): "Tatuajes en el cielo y en la tierra" (acerca de Ulrico Schmidl y de la primera fundación de Buenos Aires), "La historia que Ruy Díaz no escribió" (sobre el historiador responsable de los Anales del descubrimiento, población y conquista de las Provincias del Río de la Plata), "El alférez y la Provisora" (basado en la autobiografía de Catalina de Erauso quien dejó los hábitos por las armas); los relatos más interesantes de Historias ocultas en la Recoleta (2000) se refieren a la época de las guerras de independencia y de la pos-independencia, cuando más urgente era el problema de la construcción de una identidad argentina: cuentos sobre Facundo Quiroga, Marco Avellaneda, Florencio Varela, Domingo Faustino Sarmiento, Bartolomé Mitre y su hijo Jorge, Juan Manuel de Rosas etc. A la historia del siglo XX pertenecen dos cuentos de Historias ocultas en la Recoleta ("Memorias de una fiesta inconclusa", sobre el asesinato de Abel Ayerza por un grupo de mafiosos sicilianos, lo cual suscita sentimientos xenófobos, y "Todo lo sólido se hace ligero en el aire", acerca de Ángel María Zuloaga, quien cruzó por primera vez los Andes en Globo) y tres relatos de Amores insólitos de nuestra historia ("La niña que murió de amor en la Tierra del Diablo", referido a Carolina Beltri, cantante cubana, "El extranjero", sobre el escritor Gabriel Iturri, y "Mirándola dormir" acerca del triángulo amoroso entre Eduardo Wilde, su esposa y Julio A. Roca).

${ }^{13}$ En esto sin duda la podemos acercar a otra 'exiliada hija', la hispanomexicana Angelina Muñiz, para quien "la forma más fácil de explorar su identidad española es a través de la novela histórica” (Ruiz Infante, 2006: 845): Muñiz ahonda en sus raíces judaicas como María Rosa Lojo en las gallegas. 
modelos, a menudo contradictorios, y la mujer, siempre, un núcleo aglutinador de tradición e innovación, de encuentro entre lo autóctono y lo foráneo: en La Princesa federal Juan Manuel de Rosas y su hija Manuela se valen del napolitano Pedro de Angelis para escribir la Historia de Argentina y modelar un imaginario desligado de la tradición europea, sobre todo anglosajona, que había imperado anteriormente; en Una mujer de fin de siglo Eduarda Mansilla, quien vivió en Estados Unidos y Francia, aporta al periodismo argentino una mirada 'desde fuera', innovadora y cosmopolita; en Las Libres del Sur Victoria Ocampo y su revista Sur permiten un proficuo y enriquecedor intercambio de lenguas, tradiciones, culturas.

En estos protagonistas de novelas históricas, por lo tanto, se asoman rasgos y problemáticas presentes en su biografia y en sus obras autobiográficas: a ellos, todos con el sello de la descolocación, de pertenecer a dos o más mundos, o a ninguno, ha dado la palabra y papeles protagónicos: una especie de 'elaboración del duelo' sublimando la microhistoria personal en la macrohistoria argentina.

\section{5. Árbol de familia: el árbol y sus raíces}

Su sucesiva novela declaradamente autobiográfica, Árbol de familia, publicada en marzo $2010^{14}$, nos devuelve directamente al tema de la identidad, ya que narra su propio historial que, con las artes de la literatura, asume el papel de Historia nacional, compartida:

Para quien nace en el exilio, el lugar de su nacimiento tiene a menudo la dudosa calidad de las copias platónicas, es un mundo "de segundo grado", en tono menor, a punto de desvanecerse, deslucido e insuficiente. De la historia y la geografía argentina, hasta entonces, sólo me habían hablado los libros de escuela, incapaces de alcanzar el esplendor de la memoria viva y el peso candente del extrañamiento. La biografía familiar - yo lo ignoraba entonces- no hacía sino repetir lo que la ensayística argentina había rastreado ya en los comienzos de la conquista del Plata: una fundación que nunca se terminó de realizar, porque las extensiones vacías u hostiles fueron pobladas con el espíritu del "campamento" y no de la permanencia, porque se las enfrentó con la ignorancia (o el desprecio) hacia los númenes de la tierra nueva (Lojo, 2010a: 101-102).

La joven narradora Rosa reconstruye los caminos divergentes de sus padres, fatalmente destinados a reunirse en el Nuevo Mundo, con una enorme riqueza de registros que parecen estar moldeados alrededor de personajes y eventos, desde la prosa poética de una Galicia mágica a tonos irónicos para vidas y elecciones extravagantes, al dolor de tragedias familiares aún vivas. Todo viene desmembrado y reunido en un rompecabezas donde los lugares y los tiempos se entrelazan para revelar las tramas oscuras del destino americano de tantas generaciones de españoles.

En el centro, el exilio desde Galicia del padre -Antón el Rojo-, mientras queda como trasfondo la emigración más bien económica de la familia materna:

Antón se obstinaba en situar en ese pasado remoto y pobre el centro de su existencia y el irrecuperable lugar de la perfección. Aquellas cosas añoradas estaban embellecidas por una distancia imposible de acortar: la del exilio. Se habían vuelto intocables, a la vez ofrecidas y selladas tras el cristal más puro del deseo. Tardé en entenderlo: mi padre había traído con él su Paraíso Perdido.

Un lugar que antaño había resultado limitado y pequeño para el adolescente ansioso por ver y conquistar la gran ciudad, una aldea de infancia sumida entre montañas, iba a convertirse, años más tarde, en el Centro del Universo, manantial, siempre renovado, de una vida tan antigua que se extraviaba en la noche de los tiempos, entre brillos de cascos romanos, y más lejos aún, de orfebrerías celtas y enormes piedras blancas brotadas del suelo, como huellas de dioses gigantescos. Ningún elemento del legado materno (la Gran Vía madrileña con sus cafés, el Paseo de la Castellana, la Cibeles, ni siquiera el Museo del Prado), pudo competir -al menos para mí- con la belleza secreta de ese mundo arcaico y por lo tanto inmortal y seguramente mágico, porque en él había quedado presa el alma de mi padre (2010a: 99-100).

\footnotetext{
${ }^{14}$ Otra obra suya del mismo año, El libro de las Siniguales y del único Sinigual (primera edición en 2010, en gallego) acompañada por las imágenes de su hija la pintora Leonor Beuter, es una fábula para adultos que retoma varios elementos de sus obras precedentes: Isolina (presente también en Árbol de familia) es una niña de Finisterre que había visto extraños seres que había definido 'las Sineguales'; ya adulta, vive ahora en una ciudad de las afueras de Buenos Aires y piensa con frecuencia en el mar de Finisterre y en sus mágicos habitantes.
} 
A la plenitud del alma vegetal de Antón el rojo, que había dejado su Paraíso Perdido en Galicia y que trata de refundarlo en su nueva patria, se contrapone la negación, la ausencia, del mundo materno:

El 'no' había sitiado, voluminoso, todo su ser, vacío y carente. La ocupaba por dentro, pujante y en ascenso, como el aire impulsado por el fuego infla un aeróstato y lo lleva hacia regiones desconocidas. Pero Ana, la bella, seguía dentro de la caja de zapatos del altillo, mientras el aire ardiente de la carencia inflaba desesperadamente su ser vacío (2010a: 149).

En aquella novela, escrita con la madurez y una conquistada conciencia identitaria de quien vuelve, 20 años después, sobre temas candentes de sus obras primerizas para cerrar el círculo de la búsqueda de sus señas de identidad, finalmente se recompone este gran fresco donde se asoman la ironía y la felicidad por armar el rompecabezas sin ya cabos sueltos o irresueltos. Lo que percibía Miguel en Canción perdida..., ya pertenece al pasado: "mi vida como una sucesión de fragmentos, de trozos, una irisación de cristales dispersos que no puedo recomponer siquiera en un 'collage' no figurativo" (1987: 45).

Llegamos así al tercer eslabón, cuando ya parecía terminada la saga del exilio y de la nostalgia: hablo de Todos éramos hijos, del 2014. Mientras que a una primera lectura había podido escribir que con este libro iniciaba un nuevo ciclo ya que era.

Todos éramos hijos, del 2014, constituye el tercer eslabón de esa trayectoria, cuando ya parece que ha concluido la saga del exilio y de la nostalgia y que está empezando un nuevo ciclo: se le puede efectivamente considerar un libro 'todo argentino' que, re-elaborando los años terribles de la dictadura militar, confía a las nuevas generaciones la definitiva tarea de reconstruir una nación casi como una enésima fundación después de las destrucciones de la dictadura. Pero, con una lectura más detenida, se le puede considerar también una pieza más en la gran novela de la construcción de la nación que no puede ni quiere prescindir de la narración de los orígenes fuera del suelo patrio. Es decir, si bien es posible leer Todos éramos hijos como una muestra de autoficción dentro del panorama de la literatura testimonial ("Este libro, más cerca de la memoria que de la Historia, transcurre sobre todo en ciertos escenarios reconocibles cuyos nombres no se han cambiado", 2014: 9), no deja de ser, al mismo tiempo, tesela de la larga saga del 'ser gallego' en tierra de Argentina con un ritmo in crescendo, confirmada por la reivindicación de un alma 'gallega' de la autora y de la protagonista.

Podemos empezar con una frase que parece sin importancia y que en cambio se puede asumir como fil rouge del libro y de mi lectura. Para reunir bajo una misma agrupación a las alumnas del Colegio que frecuenta Frik, la joven protagonista, es suficiente afirmar en forma lapidaria: "La mayoría iba a quedarse en el país donde todas habían nacido, aunque algunos de sus padres hubieran nacido en otro" (2014: 16). Es decir, la mayoría de las alumnas del colegio son 'nuevas' argentinas, constituyen una 'segunda generación' decidida a quedarse en el país porque se sienten parte de él, aunque la mayoría de sus padres fueran inmigrantes.

Un poco más adelante, la narradora da cuenta de su difícil condición de inmigrante hija, que "no se sentía plenamente hija y menos aún, afincada en la tierra donde había caído [más bien] desubicada en el tiempo y en el espacio" (2014: 22), producto de la emigración materna y del exilio paterno que resume utilizando los mismos topoi de Árbol de familia:

Tanto su madre como su padre eran españoles, aunque en eso radicaba quizá lo único que tenían en común. Antes de que Frik supiese lo que era la lucha de clases, la lucha de culturas y la lucha de géneros, la había experimentado en su propia casa, en la guerra cotidiana que ellos reproducían. Ana, la madrileña, criatura de ciudad, hija verdadera o supuesta de hidalgos venidos a menos, y Antonio, campesino de alma vegetal, criatura del bosque, árbol que había hechado a andar, desenraizado por los vientos del progreso y el destierro, ahuecado como la madera de una dorna, esa barca legada por los vikingos, que cada gallego llevaba dentro de su cuerpo para cruzar el océano (2014: 22).

Como se puede apreciar, noticias escuetas y casi irónicas en registro realista y cotidiano, versus registro lírico y hasta épico. Y es este el registro que se asoma cuando, ya en la red de la represión y de la muerte, de la desaparición de amigos y maestros, Frik quiere olvidar esa historia que bien puede ser parte de la literatura testimonial argentina del posconflicto, de la cual había empezado a sentirse parte, y perderse en un espaciotiempo utópico propio de quien no tiene patria, o tiene más de una: "Frik, gallega errante, inquilina de una patria prestada" (2014: 107) - exactamente como Miguel de Canción perdida...-: 
... escuchaba el mandato de volver al lugar en el que nunca había estado, el único donde la tierra que se pisaba era real y no volaba hacia la nada, disuelta por el viento de la llanura. Donde se podían echar raíces, como los árboles de cuya sustancia estaba echa el alma humana. Las almas vagaban, perdidas, por espacios sin sentido, ciegas y sordas, hasta que lograban volver al bosque donde corría la savia desde la raíz a la copa y las ramas cargadas daban fruto (2014: 106).

Pero -parecen sugerirnos Lojo y sus alter ego, Irene, Rosa, Frik- no solo no es posible el regreso, el desdesarraigo, sino que es improrrogable la asunción de su propio tiempo para que esas tragedias - tanto la Guerra Civil española como la dictadura argentina- no provoquen nunca más exilios, violencias y desapariciones: "Desde donde hubiese venido, ahora estaba otra vez sumergida en una Historia que iba fatalmente hacia adelante sin dejarle más escapatoria que explorar, con nuevos ojos, los paisajes del dolor que marcaban todo destino humano" (2014: 108). Ya no quedan dudas, es inútil buscar consuelo en el pasado, en la historia y en los clásicos grieco-latinos:

Al derecho y al revés, hacia atrás y hacia adelante, la historia de los campesinos despojados de sus tierras después de la Guerra civil, en el umbral de la era cristiana, evocaba la de su padre. Se refractaría y se repetiría del otro lado del mar sobre los miembros de su propia generación, partidos también a otros exilios. Para varios de ellos, ya no habría retorno (2014: 192).

Quizá solo en esta descolocación provocada por la violencia, Frik y su generación se reconocen como argentinos, y lo que hay que narrar ahora es otra historia, que parte de Madres e Hijos que luchan para no olvidar, no su propia historia, sino la del Nunca Más que otra vez pertenece al Viejo y al Nuevo Mundo.

\section{Referencias bibliográficas}

Grillo, Rosa Maria (2011), "El nuevo descubrimiento de América: la Argentina de María Rosa Lojo, una 'exiliada hija"”, en Manuel Aznar Soler y José Ramón López GARCÍA (coords.). El exilio republicano de 39 y la segunda generación. Sevilla: Renacimiento, págs. 572-577.

(2013), "El nuevo descubrimiento de América en femenino: María Rosa Lojo y las mujeres argentinas”, en María Teresa González de Garay Fernández y Juan Aguilera Sastre (coords.). El exilio literario de 1939, 70 años después. Logroño: Universidad de la Rioja, págs. 185-201.

Lojo, María Rosa (1987). Canción perdida de Buenos Aires al Oeste. Buenos Aires: Torres Agüero.

-----, -------- (1996a), "Nuevas fronteras en el fin del milenio", Cuadernos Americanos. Nueva época, n’. 56, págs. 71-86.

(1996b), "Posmodernidad: otra lectura de la 'barbarie"”, Letras, n’. 33, Universidad Católica Argentina, págs. 55-61.

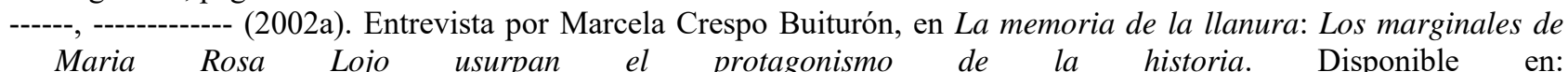
http://www.cervantesvirtual.com/fichaobra.html?ref=32076

-----, --------- (2006), "Mínima autobiografía de una «exiliada hija»", en Manuel Fuentes y Paco Tovar (eds.). L’exili literari republicá. Tarragona: URV, págs. 87-96.

-----, --------- (2008), "Escribir con ojos de libélula", en Daniel Altamiranda y Esther Pasqués (eds.). Creación y proyección de los discursos narrativos. Buenos Aires: Dunken.

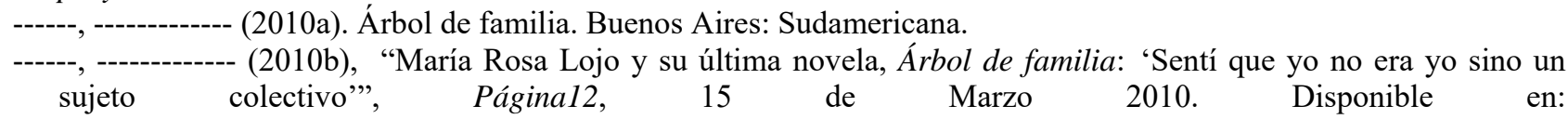

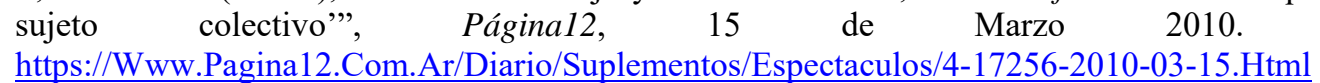

----- (2014). Todos éramos hijos. Buenos Aires: Sudamericana.

(2016), "Presentación", en María Rosa Lojo (ed.). Galicia en la Argentina: una identidad transatlántica, en Olivar, vol. 17, nº. 25. Disponible en: http://www.olivar.fahce.unlp.edu.ar/article/view/OLIe001

Manea, Norman (2006). La quinta impossibilità. Scrittura d'esilio. Milano: Il Saggiatore.

Rivera, Susana (1999). Última voz del exilio. Madrid: Hiperión.

Ruiz Infante, Josefina (2006), "Las novelas de Angelina Muñiz: obras de un exilio heredado”, en Manuel Aznar Soler (coord.). Escritores, editoriales y revistas del exilio republicano de 1939. Sevilla: Renacimiento, págs. 841-848. 